The University of Southern Mississippi

The Aquila Digital Community

Faculty Publications

$1-1-2010$

\title{
Environmental Correlates of Abundances of Mosquito Species and Stages In Discarded Vehicle Tires
}

Donald A. Yee

University of Southern Mississippi, donald.yee@usm.edu

Jamie M. Kneitel

California State University

Steven A. Juliano

Illinois State University, sajulian@il-stu.edu

Follow this and additional works at: https://aquila.usm.edu/fac_pubs

Part of the Entomology Commons

\section{Recommended Citation}

Yee, D. A., Kneitel, J. M., Juliano, S. A. (2010). Environmental Correlates of Abundances of Mosquito Species and Stages In Discarded Vehicle Tires. Journal of Medical Entomology, 47(1), 53-62.

Available at: https://aquila.usm.edu/fac_pubs/15155

This Article is brought to you for free and open access by The Aquila Digital Community. It has been accepted for inclusion in Faculty Publications by an authorized administrator of The Aquila Digital Community. For more information, please contact Joshua.Cromwell@usm.edu. 


\title{
Environmental Correlates of Abundances of Mosquito Species and Stages in Discarded Vehicle Tires
}

\author{
DONALD A. YEE ${ }^{1,2}$, JAMIE M. KNEITEL ${ }^{3}$, and STEVEN A. JULIANO ${ }^{1}$ \\ School of Biological Sciences, Behavior, Ecology, Evolution, \& Systematics Section, Illinois State \\ University, Normal, IL 61790-4120
}

\begin{abstract}
Discarded vehicle tires are a common habitat for container mosquito larvae, although the environmental factors that may control their presence or abundance within a tire are largely unknown. We sampled discarded vehicle tires in six sites located within four counties of central Illinois during the spring and summer of 2006 to determine associations between a suite of environmental factors and community composition of container mosquitoes. Our goal was to find patterns of association between environmental factors and abundances of early and late instars. We hypothesized that environmental factors correlated with early instars would be indicative of oviposition cues, whereas environmental factors correlated with late instars would be those important for larval survival. We collected 13 species of mosquitoes, with six species (Culex restuans, Cx. pipiens, Aedes albopictus, Cx. salinarius, Ae. atropalpus, and Ae. triseriatus) accounting for $\approx 95 \%$ of all larvae. There were similar associations between congenerics and environmental factors, with Aedes associated with detritus type (fine detritus, leaves, seeds) and Culex associated with factors related to the surrounding habitat (human population density, canopy cover, tire size) or microorganisms (bacteria, protozoans). Although there was some consistency in factors that were important for early and late instar abundance, there were few significant associations between early and late instars for individual species. Lack of correspondence between factors that explain variation in early versus late instars, most notable for Culex, suggests a difference between environmental determinants of oviposition and survival within tires. Environmental factors associated with discarded tires are important for accurate predictions of mosquito occurrence at the generic level.
\end{abstract}

\section{Keywords}

Aedes; bacteria; Culex; detritus; microorganisms

\begin{abstract}
Discarded vehicle tires are an important artificial habitat for the larvae of numerous species of disease-carrying container mosquitoes (reviewed in Yee 2008). Tires are important, in part, because of their abundance and proximity to human habitation, and because they are potentially more durable than natural containers (e.g., tree holes). Moreover, tires are an important means of transportation for native (Berry and Craig 1984) and invasive species (Hawley et al. 1987, Peyton et al. 1999). Although the importance of tires as a habitat for container mosquitoes is well documented, there is surprisingly little information about how environments in and around tires relate to mosquito populations and communities.
\end{abstract}

\footnotetext{
(C) 2010 Entomological Society of America

${ }^{1}$ School of Biological Sciences, Behavior, Ecology, Evolution, \& Systematics Section, Illinois State University, Normal, IL 61790-4120 (donald.yee@usm.edu).

2Present address: Department of Biological Sciences, University of Southern Mississippi, Hattiesburg, MS 39460.

${ }^{3}$ Department of Biological Sciences, California State University, Sacramento, Sacramento, CA 95819-6077.
} 
Understanding the environmental factors that affect oviposition and larval survival in tires may be of practical importance for understanding risk of disease transmission in different kinds of habitats, and may aid in planning more effective vector control strategies.

The presence of mosquito larvae in a container is the result of two processes: female oviposition choice and larval survival. Female mosquitoes use a variety of sensory cues to locate potential oviposition sites, including olfactory (e.g., volatiles from the aquatic habitat), tactile (e.g., container surfaces), and visual (e.g., color) cues (Bentley and Day 1989, Clements 1999). Female responses to these cues are likely to be selected to maximize reproductive success through ovipositing in high quality larval habitats; however, given the natural variation among habitats, most sites are likely suboptimal for attaining the highest potential fitness. Thus, we may expect to find larvae in locations that are far from ideal to maximize female fitness. Culex spp. lay eggs on the water's surface, and these hatch soon after oviposition; in contrast Aedes spp. lay eggs above the water line, and these may hatch when flooded, but hatching may be delayed, so that hatching stimuli also influence abundances of larvae (Clements 2000). After hatching, survival of larvae depends on availability of food resources (detritus, microorganisms), severity of intra- and interspecific interactions (competition, predation), and tolerances to physical factors (e.g., $\mathrm{pH}$, temperature, salinity, drying). Thus, the actual number of offspring produced from a given female is likely a function of a female's ability to find oviposition sites and the quality of those locations. How these two forces shape the abundance and prevalence of mosquito larvae in tires is essentially unexplored.

There have been several studies that have focused on how environmental factors affect tireinhabiting mosquitoes (see Yee 2008). One of the most thorough studies was completed by Beier et al. (1983b), who examined how a variety of water chemistry and habitat variables affected mosquitoes in a large tire yard in Indiana. Shading by overhanging vegetation was an important factor affecting mosquito communities, and several measured factors (e.g., turbidity, color) appeared to affect the abundance of some species, but few habitat and water chemistry variables were correlated with mosquito abundances (Beier et al. 1983b). These nonsignificant results may be attributed to the small number of tires sampled per time period (five shaded and five exposed tires) and the limited geographic range of the study (a single tire site). In fact, most studies that have investigated associations between mosquitoes and the tire environment have been limited to a single county (Beier et al. 1983a,b, Costanzo et al. 2005, Kling et al. 2007); there have been no investigations of the relationship between many environmental parameters (e.g., tire size, microorganism abundances, detritus) and mosquito community composition across a wide geographic area, where significant variation in species composition and such environmental factors is expected to occur.

We surveyed tires across four counties in Illinois to understand associations between tire environments and species and stages of mosquitoes. These counties were assumed to include a wide range of environmental factors, including human population density. Besides environmental factors, we recorded numbers of early and late instar larvae. With these data, we tested the hypotheses that distinct environmental factors are important for different stages and different species of mosquitoes. We assumed that because early instars (first and second) only were $1-2 \mathrm{~d}$ old their presence in a tire was most closely related to oviposition responses of females to specific environmental factors, and less likely the result of factors related to survival. Conversely, remaining instars (third, fourth, pupae) were expected to have been in the aquatic tire environment for many days, and thus we assumed that their presence would be most closely related to specific environmental factors affecting larval growth and survival within the tire environment. Under these assumptions, we predicted that if early and late instars of the same species displayed consistent associations with the same environmental factors, then we could conclude that factors favoring oviposition and survival 
were positively associated. However, if early and late instars each were associated with different environmental factors, then we could conclude that some factors had important associations with one stage, but not on the other. For example, we might assume that factors related to the terrestrial matrix (e.g., human population density) could affect female oviposition (early instars), but be largely unimportant to larval survival (late instars), which might depend on food supply, competition, and predators. Alternatively, some factors may be important for both eliciting oviposition responses and for larval success (e.g., detritus, as an indicator of food availability). Support for our hypotheses would come in the form of similarities in the associations between environment factors and different instars and different species. We acknowledge that a lag may occur between oviposition and the values of an environmental factor(s) a female may have responded to, such that a particular environmental parameter may have changed during the one or more days since oviposition and when we sampled a tire. This fact may not necessarily affect general patterns we are attempting to identify, as tires within a site should all be affected in a similar manner to environmental changes (e.g., rain fall, temperature). For many tire-inhabiting species, there are few or no data linking oviposition or survival to aspects of the tire environment, and thus these data could provide valuable predictive information regarding patterns of larval abundance.

\section{Materials and Methods}

Tires were sampled in four counties located in central Illinois (Sangamon, Fayette, Effingham, and St. Clair) (Table 1). Sites within counties were $\approx 10-150 \mathrm{~km}$ apart. Each county contained one or two tire sites from which 9-12 tires were sampled on two occasions: late May to early June or late July to early August (hereafter spring or summer, respectively). All sites were located near human habitation or active businesses. We estimated that sites in St. Clair County each contained several hundred abandoned tires, whereas the urban dump in Sangamon County had approximately three dozen tires located in the back of a dump truck. Tire dealers in Sangamon (spring sampling only) and Fayette Counties sold a variety of new and used tires (i.e., automobile, truck, construction vehicles), with each business having $\approx 100$ tires located outdoors. Residential tires sampled in the summer in Sangamon County were abandoned in and around occupied and unoccupied homes in a $1,000 \mathrm{~m}^{2}$ area. The nine tires sampled in the summer from this site were all that were available at that time that met our criteria (see below). The rural salvage yard in Effingham County contained $\approx 100$ tires distributed among automobile salvage.

For each tire we measured a suite environmental factors in three broad categories that have been shown to affect container mosquito populations (Yee 2008): microorganisms (protozoan richness, protozoan total abundance, bacterial biomass production, algae), detritus and nutrients (hereafter, detritus) (leaves, twigs, seeds, animal detritus, fine detritus, conductivity), and those related to habitat size or the terrestrial matrix (hereafter, habitat) (human density, canopy cover, tire size, tire volume).

Microorganisms, including protozoans and bacteria, are the primary food source for container mosquitoes and represent the living base of container food webs (Merritt et al. 1992). Detritus represents the nonliving input of energy and nutrients into tires, and has been shown to be important for production of larvae (Merritt et al. 1992, Yee and Juliano 2006). Variation in detritus types may affect interspecific competitive outcomes (Daugherty et al. 2000, Yee et al. 2007a, Murrell and Juliano 2008). We assumed that the microorganism and detritus factors we measured could directly affect larvae success (late instars) or oviposition patterns (early instars). Although the habitat factors also could directly influence larvae (e.g., via effects on temperature), we assumed that it was much more likely to influence larvae indirectly by affecting oviposition patterns (early instars). 
At both sampling times to ensure we only sampled tires in which mosquito larvae could survive we constrained our sampling to tires that contained mosquito larvae. From these tires, we randomly selected tires to sample and labeled them to avoid resampling. We also attempted to avoid tires with the predator Toxorhynchites rutilus (Coquillett), a predator known to affect negatively mosquito populations. We did retain tires that we already sampled that, upon enumeration of larvae, were found to contain $T X$. rutilus, although such encounters happened in only three tires in summer at one site.

For each location, we generated an estimate of human population density based on data from the 2000 U.S. Census (http://www.census.gov/). Specifically, we identified the county subdivision for each tire location, and then determined the area and population size of that subdivision to generate a population density (kilometers square) coincident with each tire site (Table 2).

We measured canopy cover above each tire using a spherical densiometer and the tire's rim diameter (tire size) as indicated on the sidewall of the tire. Before sampling mosquitoes, we removed $125 \mathrm{ml}$ of fluid for conductivity and microorganism measurements and kept this sample in the dark and on ice for transport to the laboratory. Then, the remaining contents of the tire were removed with kitchen basters, hand pumps, or by cutting a hole in the side wall of the tire. The volume of water from each tire also was measured. After removal of the contents, the tire was rinsed with $125 \mathrm{ml}$ of tap water. Tire contents and the rinse were taken to the laboratory for quantification of mosquitoes and detritus. We separated detritus into five categories: twigs (including bark), leaves, seeds (including fruit), fine particulates (including soil), and animal detritus (dead invertebrates). Any inorganic detritus (e.g., rocks) was discarded. Detritus was dried at $50^{\circ} \mathrm{C}$ for $\geq 48 \mathrm{~h}$ and weighed to the nearest $0.0001 \mathrm{mg}$ using a Cahn microbalance (Cahn Instruments, CA).

The $125 \mathrm{ml}$ sample of water was used to measure conductivity, algae, protozoans, and bacterial productivity. Conductivity, which measures total ion concentration and has been shown to affect communities in mosquito-dominated containers (Yee and Juliano 2007), was measured using a Cole Parmer conductivity meter $(\mu \mathrm{MHOS} / \mathrm{cm})$. We quantified watercolumn algae via measurements of chlorophyll $a\left(\mathrm{mg} / \mathrm{m}^{-3}\right)$ (following Kling et al. 2007). Production of new bacterial biomass was quantified by estimating protein synthesis (hereafter PS) using a tritiated L-leucine $\left(4,5-{ }^{3} \mathrm{H}, 50 \mathrm{Ci}\right.$ mmol-1) incorporation assay. The Lleucine incorporation assay technique is specific to bacteria in aquatic systems (Riemann and Azam 1992) and has been used to quantify bacterial productivity in container mosquito experiments (Kaufman et al. 2001, Yee et al. 2007a,b, Murrell and Juliano 2008). We measured water column PS following Kirchman (1993) and refined by Kaufman et al. (2001) for container systems. Finally, protozoan richness and abundance in each tire were quantified by first gently mixing samples, extracting $1.0 \mathrm{ml}$ into a Sedgewick rafter cell, and enumerating at $100 \times$ magnification in a phase contrast microscope (Kneitel and Chase 2004). Preliminary tests indicated that this technique captured $87 \%$ of the protozoan diversity in samples. Protozoan identifications were made based on Pennak (1989) and Foissner and Berger (1996). Similar methods for protozoans have been used in another container mosquito system (i.e., tree holes, Yee et al. 2007c).

We enumerated all mosquito larvae and separated them into two size classes: early (first and second) and late instars (third, fourth, and pupae). Because of the large numbers of early instars requiring identification, and because of mortality incurred during development into later instars, we used a sub-sampling protocol to assign individuals to species. We first counted all early instars within a sample and then reared these individuals to the third stage or later, and identified 100 randomly chosen larvae to species. We used the proportion of identified larvae to assign species affiliations to the initial number of early instars. All larvae 
were identified if $<100$ remained. Larvae collected as late instars all were identified to species. Pupae were allowed to eclose and were identified to species, except for Culex, which, because of difficulties in identification among species, were identified only to genus.

\section{Statistical Analyses}

Two multivariate analysis of variance (MANOVA) models were used to analyze the abundance data. In each model, season and site were used as independent (predictor) variables. The first model included mosquito richness and abundance (regardless of species) and abundance of each species as dependent variables, and the second model included a suite of environmental factors as dependent variables (SAS Institute, Inc. 2004). Contributions to significant multivariate effects were interpreted using standardized canonical coefficients (Scheiner 2001). To meet assumptions of normality and homogeneous variances mosquito abundance data were square root +1 transformed.

Responses of mosquito stages (early, late) to the suite of environmental factors for each season were assessed using canonical correspondence analysis (CCA). CCA is an ordination technique that considers species and environmental variables simultaneously, and is particularly useful when there are underlying unimodal abundance distributions (ter Braak 1986). This technique produces canonical axes that are constrained to optimize their relationship with a set of environmental variables represented as vectors (ter Braak and Verdonschot 1995). The lengths of these vectors indicate the rate of change in that environmental variable; shorter vectors indicate little variation whereas longer arrows reflect more variation among samples. Areas that are perpendicular to the vectors represent no change in that variable. As with other ordination techniques (e.g., principal components analysis) the axes are orthogonal and thus are uncorrelated with one another, although vectors on the same axis that form acute angles are positively correlated, those that form obtuse angles are negatively correlated. Species are represented by points on the diagram that characterize approximate weighted means of the species with respect to environmental variables. The distance between species points and vectors identifies the relative importance of environmental variables in explaining species abundance patterns; points closer to vectors are more influenced by that environmental variable than points farther away. The statistical significance of each environmental axis was evaluated by permutation tests, after first reducing the overall suite of environmental variables using a step-wise method based on Akaike's Information Criterion (AIC) (Akaike 1973). AIC is analogous to a goodness-of-fit test, and allows for the determination of which of two models provide a better fit (i.e., have a lower AIC score, Motulsky and Christopoulos 2004). We restricted CCA to taxa that were present in at least two counties and had mean densities greater than one individual per tire regardless of stage (hereafter, common species). Because CCA is relatively sensitive to missing values (no larvae for a species present in a tire), we felt it necessary to restrict the analysis of species that were relatively common (mean density greater than one individual per tire) and were not geographically isolated (present in at least two counties). Tires lacking these common species were dropped from analyses. CCA was performed using the statistical package R (http://www.r-project.org).

Because it is possible that species respond to one another rather than to environmental factors, we performed tests for associations between species pairs regardless of stage, and between stages within species. We only compared those species that occurred together at the same locations regardless of how many tires were occupied, and thus more species were considered than in CCA. Significance was based on comparison of presence-absence data using Fisher Exact tests in R. A Bonferonni correction (Sokal and Rohlf 1995) for multiple comparisons was employed to reduce the risk of committing a type I error. 


\section{Results}

We encountered 13 species of mosquitoes, the most common being $C X$. restuans (Theobald) (39.5\% of all mosquito larvae sampled), Culex pipiens (L,) (22.9\%), Aedes albopictus (Skuse) (14.7\%), CX. salinarius (Coquillett) (14.3\%), Ae. atropalpus (Coquillett) (5.4\%), and Ae. triseriatus (Say) (1.7\%) (Table 1). Abundances of other species (Anopheles punctipennis (Say), An. quadrimaculatus (Say), Ae. hendersoni (Cock-erell), Ae. japonicus (Theobald), $C x$. territans, Orthopodomyia signifera, and Toxorhynchites rutilus) constituted $<3 \%$ of individuals.

For species, MANOVA resulted in a significant effect of season (Pillai's trace $=0.44, F(9$, $117)=10.19, P<0.001$ ), site (Pillai's trace $=1.32, F(54,732)=3.84, P<0.001)$, and the interaction (Pillai's trace $=0.66, F(36,480)=2.64, P<0.001) . C X$. restuans (Standardized Canonical Coefficient $=-0.583), C X$. salinarius $(\mathrm{SSC}=-1.304)$, and mosquito abundance per tire ( $\mathrm{SCC}=+1.386)$ made the largest contributions to the significant season by site interaction. $C x$. restuans and $C x$. salinarius populations experienced a decline from spring to summer (Table 1). Overall mosquito abundance increased from spring to summer, with the exception of one site in St. Clair County (Table 1).

For the environmental variables, MANOVA also resulted in a significant effect of season (Pillai's trace $=0.47, F(13,113)=7.85, P<0.001)$, site (Pillai's trace $=2.38, F(78,708)=$ $5.96, P<0.001$ ), and the interaction (Pillai's trace $=0.84, F(52,464)=2.38, P<0.001)$. Specifically, cover (Standardized Canonical Coefficient $=+1.810$ ) and conductivity (SCC= +0.557 ) made the largest contributions to the significant season by site interaction. Conductivity values were variable between spring and summer across sites, with the largest increase at the site in Effingham (Table 2).

For CCA in the spring, step-wise selection of environmental variables reduced the factors from fourteen to eight, including three types of detritus (fine, leaf, seed), two microorganism factors (PS, protozoan abundance), and three factors in the habitat category (canopy cover, human density, tire size) that combined explained $38.9 \%$ of the variation among species ( $F$ $(8,50)=3.971, P=0.005$, Fig. 1$)$. For summer, step-wise selection did not result in the removal of any factor, and thus the final model contained all fourteen factors that explained $43.2 \%(F(14,50)=2.713, P=0.029)$ of the variation among species and stages (Fig. 2).

CCA ordination of tires in spring yielded two general environmental gradients: a detritus (fine, leaf, seed) versus human density gradient, and a tire size versus canopy cover and microorganism (protozoan abundance, bacterial productivity) gradient. In general, these gradients pointed to two mosquito assemblages, with Aedes being more abundant in tires surrounded by low human population densities but with high detritus amounts (i.e., fine, leaf, seeds), whereas Culex were more likely found in tires with greater protozoan abundance and lower canopy cover (Fig. 1). Although early and late instars for each species were found largely along the same environmental gradient (e.g., Ae. triseriatus, $C X$. salinarius), $C x$. restuans early instars were influenced by tire size, whereas late instars were more influenced by microorganisms (PS, protozoan abundance) and canopy cover (Fig. 1).

As in spring, the CCA ordination plot for summer revealed two general gradients, with one gradient representing detritus (fine, animal, twig, conductivity) versus tire size, tire volume, and protozoan abundance, whereas the second gradient represented bacterial productivity and seeds versus canopy cover, algae, human density, and protozoan richness. These gradients revealed striking differences between genera, with Aedes being found in tires with high amounts of seeds and bacterial productivity, but with low or absent amounts of algae and protozoans, high canopy cover, and in areas with low human densities (Fig. 2). Culex were found mainly in high volume tires in areas of high human density with low amounts of 
detritus (i.e., fine, conductivity, animal, twig). The main exception to the pattern for Culex was $C x$. salinarius, with late instars likely to be found in tires with high amounts of detritus, and where early instars were likely to be found in tires in the open with high amounts of algae and in proximity to humans (Fig. 2).

Regardless of season, a typical Aedes tire would most likely contain high amounts of detritus, be located in areas with low human density, and be occupied by both early and late instars of the same species. Conversely, a typical Culex tire would be relatively large and contain high concentrations of protozoans and bacteria, be found in association with high human densities, and be less likely than a typical Aedes tire to contain both early and late instars.

In spring, $C x$. salinarius presence was significantly related to $C X$. pipiens $(P=0.011)$ and Ae. albopictus $(P=0.021)$. All other comparisons were nonsignificant. In summer, only one pair was significantly correlated (Ae. triseriatus and Ae. atropalpus, $P=0.008$ ). Associations between stages within species were uncommon. Only $C X$. salinarius $(P=0.035)$ and $A e$. atropalpus ( $P=0.010$ summer) in spring, and Ae. albopictus $(P=0.038)$ in summer, yielded significant (all positive) associations between stages.

\section{Discussion}

Mosquito larvae community composition within tires across central Illinois was similar to that found in other more limited studies for this state (Baumgartner 1988, Novak et al. 1990, Lampman et al. 1997, Kling et al. 2007), although we did not detect An. barberi (Lampmann et al. 1997, Kling et al. 2007) or CX. tarsalis (Baumgartner 1988). This survey did record one of the first occurrences of the invasive species Ae. japonicus in tires in Illinois (Table 1). Our data suggest three general patterns in tire mosquito communities. First, regardless of season, patterns of abundance for early and late instars were generally associated with the same environmental factors especially for Aedes, although early and late instars of the same species were often not significantly associated within tires. Second, there were clear differences between the common mosquito genera (Culex and Aedes) in the suite of environmental factors important for larval presence, and third, there were few associations among species pairs. Taken together, these results support our hypothesis that distinct environmental factors are important for different stages and species of mosquitoes. Moreover, the predictive power of environmental factors seems to be greater at the genus, rather than at the species level. In general, although the patterns we identified could emanate from the effects of inter- and intraspecific interactions on larval development and abundance, we must be cautions with assigning process based on pattern alone.

Variation in early and late instars of common mosquito species in tires was often associated with the same environmental factors, although the strength of these species-environmental associations (i.e., the relative position of species points near vectors, Figs. 1 and 2) did vary between instars. This suggests a difference in the importance of some environmental factors for oviposition and larval survival (e.g., microorganism and Culex sp., see below). There were several examples of factors affecting one stage, but not the other stage (i.e., greater distances between species points in relation to vectors, Figs. 1 and 2). The most notable examples of this included Ae. albopictus, Ae. triseriatus, $C x$. restuans, and $C x$. salinarius in spring, and $C_{x}$. restuans and $C_{x}$. salinarius in summer (Figs. 1 and 2). The strongest example of this difference between early and late instars was for $C X$. restuans. Culex restuans has been shown to avoid conspecifics and prefer more nutrient-rich containers for oviposition (Reiskind and Wilson 2004). The results of Reskind and Wilson (2004) are corroborated in this study, where early and late instar $C X$. restuans were affected by different environmental factors (Fig. 1 and 2) and there was no correlation between stages. 
Microorganism populations were highly correlated with early instars but less correlated with late instars of several species (CX. restuans (summer), Ae. albopictus (spring), and $C X$. pipiens (spring and summer) [Fig. 1 and 2]). Microorganisms may stimulate egg laying in females (Bentley and Day 1989), leading to greater densities of newly hatched larvae, although feeding by developing larvae may depress those populations (Kaufman et al. 2001, Yee et al. 2007b) making microorganisms less important predictors of later instars. Early instar Ae. albopictus and Ae. triseriatus were generally affected by the same factors (i.e., detritus) in both seasons with late instars showing less of an influence by those factors. In contrast, Ae. atropalpus late instars were related in a similar way as early instars of other Aedes. Therefore, the oviposition cues that might lead to the presence of early instar Ae. atropalpus appear to be weaker than those for other Aedes in tires. Past work has shown that algae is important in the native rock pool habitat of Ae. atropalpus (Beier et al. 1983b), although we found no association between Ae. atropalpus and algae. It remains unknown why Ae. atropalpus invaded tires during the 1980s (Berry and Craig 1984), but we speculate that the new strain that developed was capable of exploiting novel food resources (e.g., fine detritus) in tires, and may use oviposition cues not used by other Aedes. These results suggest that the way that species respond to specific environmental factors is complex, and points to a difficulty in attempting to predict the response of any tire-inhabiting species to any single factor among many. An important research goal for the future will be to test individual factors and combinations of factors experimentally to assess the degree that each is related to oviposition and larval survival.

CCA did identify more general relationships that may be useful in predicting larval abundance patterns. Detritus was predictive for populations of Aedes, whereas microorganisms and habitat factors were stronger predictors for Culex (Figs. 1 and 2). The difference between factors for each genus could be related to a number of generic-level attributes, including blood seeking and oviposition behavior of adults, and competitive ability and feeding behavior of larvae. For instance, Culex as a group tend to filter feed on microorganisms from the water column (Dahl et al. 1988, Merritt et al. 1992), although this trait can be flexible (Yee et al. 2004). Thus, we might expect that water-column microorganisms, like those that we measured, would be more important for Culex compared with Aedes, which primarily feed on microorganisms attached to detrital surfaces (Merritt et al. 1992). It appears unlikely that specific bacterial groups would stimulate oviposition, as recent work has shown that although bacterial diversity varies among tires, this variation is not associated with differences in mosquito presence (Ponnusamy et al. 2008). One microorganism group, protozoans, were more important for Culex than Aedes, with high associations for early $C_{X}$. salinarius and late $C_{X}$. pipiens and $C_{X}$. restuans in spring, and early $C X$. restuans and early and late $C_{X}$. pipiens in summer (Fig. 1 and 2). Protozoans often are important prey for mosquito larvae (Conchran-Stafira and von Ende 1998, Eisenberg et al. 2000, Kaufman et al. 2002, Kneitel 2007, Yee et al. 2007c), although there are no data testing whether protozoans affect patterns of oviposition. Gravid females of several species of container mosquitoes prefer substrates with bacteria for oviposition (Maw 1970, Ikeshoji et al. 1975, Trexler et al. 2003), and our data identified bacterial productivity (PS) as important for both early and late instars of Aedes during spring (Fig. 1) and some Culex in summer (Fig. 2). Larval competition could be another factor explaining the apparent segregation of genera indicated by CCA, although there are no studies between these genera beyond those that have examined competitive interactions between Ae. albopictus and $C X$. pipiens (Carrieri et al. 2003, Costanzo et al. 2005). The fact that Aedes and Culex presence in tires are influenced by different suites of environmental variables may be useful when designing vector control strategies, especially as these two groups vary in their capability to vector disease. 
Besides explanations based on larvae, interspecific differences in adult behavior also may explain the broad patterns identified here. For instance, human population density positively affected almost all Culex (Figs. 1 and 2), a result reflecting the fact that all of these Culex species are peridomestic (Vinogradova 2000, Joy et al. 2003, Joy 2004, Costanzo et al. 2005, Joy and Sullivan 2005). Unexpectedly, we found populations of Ae. albopictus to be negatively associated with human density (Figs. 1 and 2) especially in spring, a result that conflicts with a more limited geographic study from Illinois (Costanzo et al. 2005) but is consistent with data from Florida (O'Meara et al. 1995, Rey et al. 2006). It is not surprising that Ae. atropalpus and Ae. triseriatus were more likely to be found in sites with lower human populations, as both species are thought to be nonperidomestic (Joy et al. 2003, Joy 2004, Joy and Sullivan 2005). Sites where Aedes were more common also tended to be rural and near forests (Fayette and Effingham counties, Table 1), which might explain why plantderived detritus (Table 2) was the most important factor in explaining their patterns of occurrence (Figs. 1 and 2). Kling et al. (2007) showed that there was a strong correlation between seeds and densities of Ae. triseriatus in tires in Illinois, a result broadly consistent with this study. The influence of the surrounding habitat has largely been ignored in past studies in tires (Yee 2008), but may yield important information about the forces that determine patterns of larval presence within tires.

Besides environmental factors affecting species abundance patterns, we also tested for correlations and associations among species. In general, CCA identified correlations within genera for the common Aedes and Culex (Figs. 1 and 2). More specifically, we identified a few significant positive pair-wise associations $(C x$. salinarius and $C X$. pipiens, $C X$. salinarius and Ae. albopictus, and Ae. atropalpus and Ae. triseriatus). The latter association was identified by Beier et al. (1983b), although those authors found a negative association with the first pair. We also identified associations between early and late instars for a few species. Although it seems clear that associations among taxa are important for the presence of some species, further work is needed to disentangle the importance of the attractiveness of conspecific and environmental factors to larval presence for tire species.

Although it is often assumed that mosquito oviposition choice drives patterns of larval presence, other biotic mechanisms may explain larval distributions (Ellis 2008). Larval survival is inextricably tied to environmental parameters present within tires, and this makes oviposition choice by females alone insufficient to predict patterns of occurrence. Because tires are likely to remain a habitat for larvae of disease-carrying mosquitoes in the near future (Yee 2008), determining all the forces responsible for larval patterns will be an important challenge for ultimately understanding patterns of disease transmission.

\section{Acknowledgments}

We thank L. J. Kling and L. M. Sala for assistance with tire sampling, L. J. Kling and K. Kirkham for quantifying algae, and S. M. Yee for helping with sorting and statistical advice. We thank R. King and the staff of East Side Health District, East St. Louis, and S. Hall, of Sangamon County Mosquito Control for assisting us in locating tire sites. This work was supported by grants to S. A. Juliano and D.A. Yee (R15 [AI]-051374) from the National Institute of Allergy \& Infectious Disease.

\section{References Cited}

Akaike, H. Information theory and an extension of the maximum likelihood principle. In: Petrov, BN.; Csaki, F., editors. 2nd International Symposium on Information Theory (Tsahkadsor, 1971). Akademia Kiado; Budapest, Hungary: 1973. p. 267-281.

Baumgartner DL. Suburban accumulations of discarded tires in northeastern Illinois and their associated mosquitoes. J. Am. Mosq. Cont. Assoc. 1988; 4:500-508. 
Beier JC, Patricoski C, Kranzfelder J. Habitat segregation among larval mosquitoes in tireyards in Indiana, USA. J. Med. Entomol. 1983a; 20:76-80. [PubMed: 6131138]

Beier JC, Patricoski C, Travis M, Kranzfelder J. Influence of water chemical and environmental parameters on larval mosquito dynamics in tires. Environ. Entomol. 1983b; 12:434-438.

Bentley MD, Day JF. Chemical ecology and behavioral aspects of mosquito oviposition. Annu. Rev. Entomol. 1989; 34:401-421. [PubMed: 2564759]

Berry WJ, Craig GB Jr. Bionomics of Aedes atropalpus breeding in scrap tires in northern Indiana. Mosq. News. 1984; 44:476-484.

Carrieri M, Bacchi M, Bellini R, Maini S. On the competition occurring between Aedes albopictus and Culex pipiens (Diptera: Culicidae) in Italy. Environ. Entomol. 2003; 32:1313-1321.

Cochran-Stafira DL, von Ende CN. Integrating bacteria into food webs: studies with Sarracenia purpurea inquilines. Ecology. 1998; 79:880-898.

Clements, AN. The biology of mosquitoes. Vol. vol. I. CABI Publishing; Cambridge, United Kingdom: 2000.

Clements, AN. The biology of mosquitoes. Vol. vol. II. CABI Publishing; Cambridge, United Kingdom: 1999.

Costanzo KS, Mormann K, Juliano SA. Asymmetrical competition and patterns of abundance of Aedes albopictus and Culex pipiens (Diptera: Culicidae). J. Med. Entomol. 2005; 42:559-570. [PubMed: 16119544]

Dahl C, Widahl L-E, Nilsson C. Functional analysis of the suspension feeding system in mosquitoes (Diptera: Culicidae). Ann. Entomol. Soc. Am. 1988; 81:105-127.

Daugherty MP, Alto BW, Juliano SA. Invertebrate carcasses as a resource for competing Aedes albopictus and Aedes aegypti (Diptera: Culicidae). J. Med. Entomol. 2000; 37:364-372. [PubMed: 15535579]

Ellis AM. Linking movement and oviposition behavior to spatial population distribution in the tree hole mosquito Ochlerotatus triseriatus. J. Anim. Ecol. 2008; 77:156-166. [PubMed: 18177335]

Eisenberg JNS, Washburn JO, Schreiber SJ. Generalist feeding behaviors of Aedes sierrensis larvae and their effects on protozoan populations. Ecology. 2000; 81:921-935.

Foissner W, Berger H. A user-friendly guide to the ciliates (Protozoa, Ciliophora) commonly used by hydrobiologists as bioindicators in rivers, lakes, and waste waters, with notes on their ecology. Fresh. Biol. 1996; 35:375-482.

Hawley WA, Reiter P, Copeland RS, Pumpuni CB, Craig GB Jr. Aedes albopictus in North America: probable introduction in used tires from northern Asia. Science. 1987; 236:1114-1116. [PubMed: 3576225]

Ikeshoji TK, Saito K, Yano A. Bacterial production of the oviposition attractants for mosquitoes on fatty acid substrates. Appl. Entomol. Zool. 1975; 10:302-308.

Joy JE, Hanna AA, Kennedy BA. Spatial and temporal variation in the mosquitoes (Diptera: Culicidae) inhabiting waste tires in Nicholas County, West Virginia. J. Med. Entomol. 2003; 40:73-77. [PubMed: 12597656]

Joy JE. Larval mosquitoes in abandoned tire pile sites from West Virginia. J. Am. Mosq. Cont. Assoc. 2004; 20:12-17.

Joy JE, Sullivan N. Occurrence of tire inhabitating mosquito larvae in different geographic regions of West Virginia. J. Am. Mosq. Cont. Assoc. 2005; 21:380-386.

Kaufman MG, Bland SN, Worthen ME, Walker ED, Klug MJ. Bacterial and fungal biomass responses to feeding by larval Aedes triseriatus (Diptera: Culicidae). J. Med. Entomol. 2001; 38:711-719. [PubMed: 11580044]

Kaufman MG, Goodfriend W, Kohler-Garrigan A, Walker ED, Klug MJ. Soluable nutrient effects on microbial communities and mosquito production in Ochlerotatus triseriatus habitats. Aqua. Microb. Ecol. 2002; 29:73-88.

Kirchman, DL. Leucine incorporation as a measure of biomass production by heterotrophic bacteria. In: Kemp, PF.; Sherr, BF.; Sherr, EB.; Cole, JJ., editors. Handbook of methods in aquatic microbiology. Lewis Publishing; Boca Raton, FL: 1993. p. 509-512. 
Kling LJ, Juliano SA, Yee DA. Larval mosquito communities in discarded automobile tires in a forested and non-forested site: detritus type, amount, and water nutrient differences. J. Vect. Ecol. 2007; 32:207-217.

Kneitel JM. Intermediate-consumer identity and resources alter a food web with omnivory. J. Anim. Ecol. 2007; 76:651-659. [PubMed: 17584370]

Kneitel JM, Chase JM. Disturbance, predator, and resource interactions alter container community composition. Ecology. 2004; 85:2088-2093.

Lampman R, Hanson S, Novak RJ. Seasonal abundance and distribution of mosquitoes at a rural waste tire site in Illinois. J. Am. Mosq. Cont. Assoc. 1997; 13:193-200.

Maw MG. Capric acid as a larvicide and as a oviposition stimulant for mosquitoes. Nature. 1970; 227:1154-1155. [PubMed: 5451117]

Merritt RW, Dadd RH, Walker ED. Feeding behavior, natural food, and nutritional relationships of larval mosquitoes. Annu. Rev. Entomol. 1992; 37:349-376. [PubMed: 1347208]

Motulsky, H.; Christopoulos, A. Fitting models to biological data using linear and nonlinear regression. A practical guide to curve fitting. Oxford University Press; Oxford, United Kingdom: 2004.

Murrell EG, Juliano SA. Detritus type alters the outcome of interspecific competition between Aedes aegypti and Aedes albopictus (Diptera: Culicidae). J. Med. Entomol. 2008; 45:375-383. [PubMed: 18533429]

Novak RJ, Steinly BA, Webb DW, Haramis L, Clarke J Jr. Farmer B, Cieslik R. Penetration rate of two pesticide carriers at a large used-tire storage facility in Chicago, Illinois. J. Am. Mosq. Cont. Assoc. 1990; 6:188-196.

O'Meara GF, Evans LF, Gettman AD, Cuda JP. The spread of Aedes albopictus and decline of Ae. aegypti (Diptera: Culicidae) in Florida. J. Med. Entomol. 1995; 32:554-562. [PubMed: 7650719]

Pennak, RW. Fresh-water invertebrates of the United States: protozoa to mollusca. Wiley-Interscience; New York: 1989.

Peyton EL, Campbell SR, Canaeletti TM, Romanowski M, Crans WJ. Aedes (Finlaya) japonicus japonicus (Theobald), a new introduction into the United States. J. Am. Mosq. Cont. Assoc. 1999; 15:238-241.

Ponnusamy L, Xu N, Stav G, Wesson DM, Schal C, Apperson CS. Diversity of bacterial communities in container habitats of mosquitoes. Micob. Ecol. 2008; 56:593-603.

Reiskind MH, Wilson ML. Culex restuans (Diptera: Culicidae) oviposition behavior determined by larval habitat quality and quantity in Southeastern Michigan. J. Med. Entomol. 2004; 41:179-186. [PubMed: 15061276]

Rey JR, Nishimura N, Wagner B, Braks MAH, O'Connell SM, Lounibos LP. Habitat segregation of mosquito arbovirus vectors in south Florida. J. Med. Entomol. 2006; 43:1134-1141. [PubMed: 17162945]

Riemann B, Azam F. Measurements of bacterial protein synthesis in eutrophic aquatic environments by means of leucine incorporation. Mar. Microb. Food Webs. 1992; 6:91-105.

SAS Institute. SAS/STAT 9.1 User's Guide. SAS Institute; Cary, NC: 2004.

Scheiner, SM.; Scheiner, SM.; Gurevitch, J. Design and analysis of ecological experiments. 2nd ed.. Oxford University Press; Oxford, United Kingdom: 2001. MANOVA. Multiple response variables and multi species interactions; p. 99-133.

Sokal, RR.; Rohlf, F. Biometry. The principles and practice of statistics in biological research. W. H. Freeman and Company; New York: 1995.

ter Braak CJF. Canonical correspondence analysis: a new eigenvector technique formultivariate direct gradient analysis. Ecology. 1986; 67:1167-1179.

ter Braak CJF, Verdonschot PFM. Canonical correspondence analysis and related multivariate methods in aquatic ecology. Aqua. Science. 1995; 57:255-289.

Trexler JD, Apperson CS, Zurex L, Gemeno C, Schal C, Kaufman M, Walker E, Watson DW, Wallace L. Role of bacteria in mediating the oviposition responses of Aedes albopictus (Diptera:

Culicidae). J. Med. Entomol. 2003; 40:841-848. [PubMed: 14765661] 
Vinogradova, EB. Culex pipiens pipiens mosquitoes; taxonomy, distribution, ecology, physiology, genetics, applied importance and control. Pensoft; Sofia, Bulgaria: 2000.

Yee DA. Tires as habitats for mosquitoes: a review of studies within the eastern United States. J. Med. Entomol. 2008; 45:581-593. [PubMed: 18714856]

Yee DA, Kesavaraju B, Juliano SA. Larval feeding behavior of three co-occurring species of container mosquitoes. J. Vect. Ecol. 2004; 29:315-322.

Yee DA, Juliano SA. Consequences of detritus type in an aquatic microsystem: assessing water quality, microorganisms, and the performance of the dominant consumer. Fresh. Biol. 2006; 51:448-459.

Yee DA, Juliano SA. Abundance matters. A field experiment testing the more individuals hypothesis for richness-productivity relationships. Oecologia. 2007; 153:153-162. [PubMed: 17401581]

Yee DA, Kaufman MG, Juliano SA. The significance of ratios of detritus types and microorganism productivity to competitive interactions between aquatic insect detritivores. J. Anim. Ecol. 2007a; 76:1105-1115. [PubMed: 17922707]

Yee DA, Kesavaraju B, Juliano SA. Direct and indirect effects of animal detritus on growth, survival, and mass of the invasive container mosquito Aedes albopictus (Diptera: Culicidae). J. Med. Entomol. 2007b; 44:580-588. [PubMed: 17695011]

Yee DA, Yee SH, Kneitel JM, Juliano SA. Richness-productivity relationships between trophic levels in a detritus-based system: significance of abundance and trophic linkage. Oecologia. 2007c; 154:377-385. [PubMed: 17713787] 


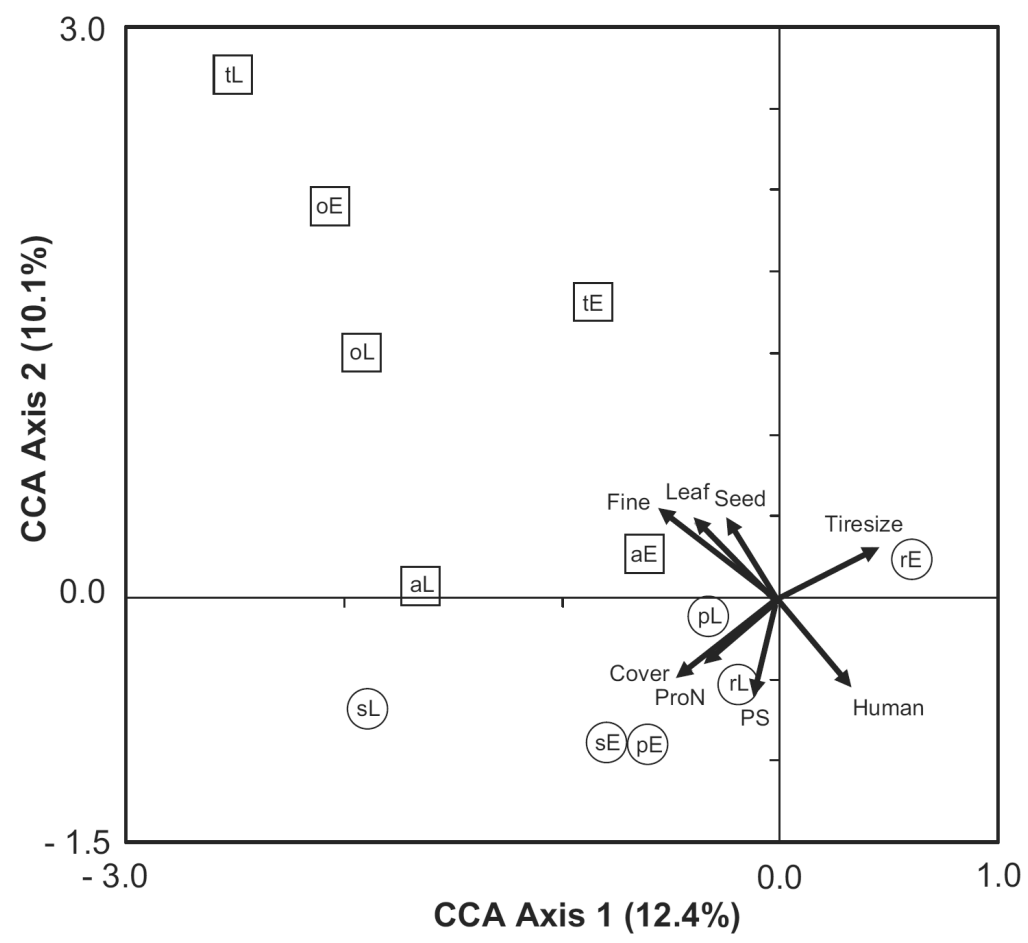

Fig. 1.

CCA biplots for mosquito species and stages and the environmental factors measured in tires in spring (May-June) 2006 for six sites within central Illinois ( $n=59$ tires). For each axis, the amount of variation explained by each axis is shown. Arrows indicate the direction and relative importance of the environmental factors (Detritus category: Fine, Leaf, Seed [including fruit]); Habitat category (Tiresize - Tire size, Cover - Canopy cover, Human Human density); Microorganism category (ProN - Protozoan abundance, PS - Bacterial productivity via protein synthesis). Species (a - Aedes albopictus, o-Ae. atropalpus, $\mathrm{t}-$ Ae. triseriatus, $\mathrm{p}-$ Culex pipiens, $\mathrm{r}-C x$. restuans, $\mathrm{s}-C x$. salinarius) and stages (E - early instars, L - late instars) are indicated within symbols. For clarity, Aedes are enclosed in squares, and Culex in circles. 


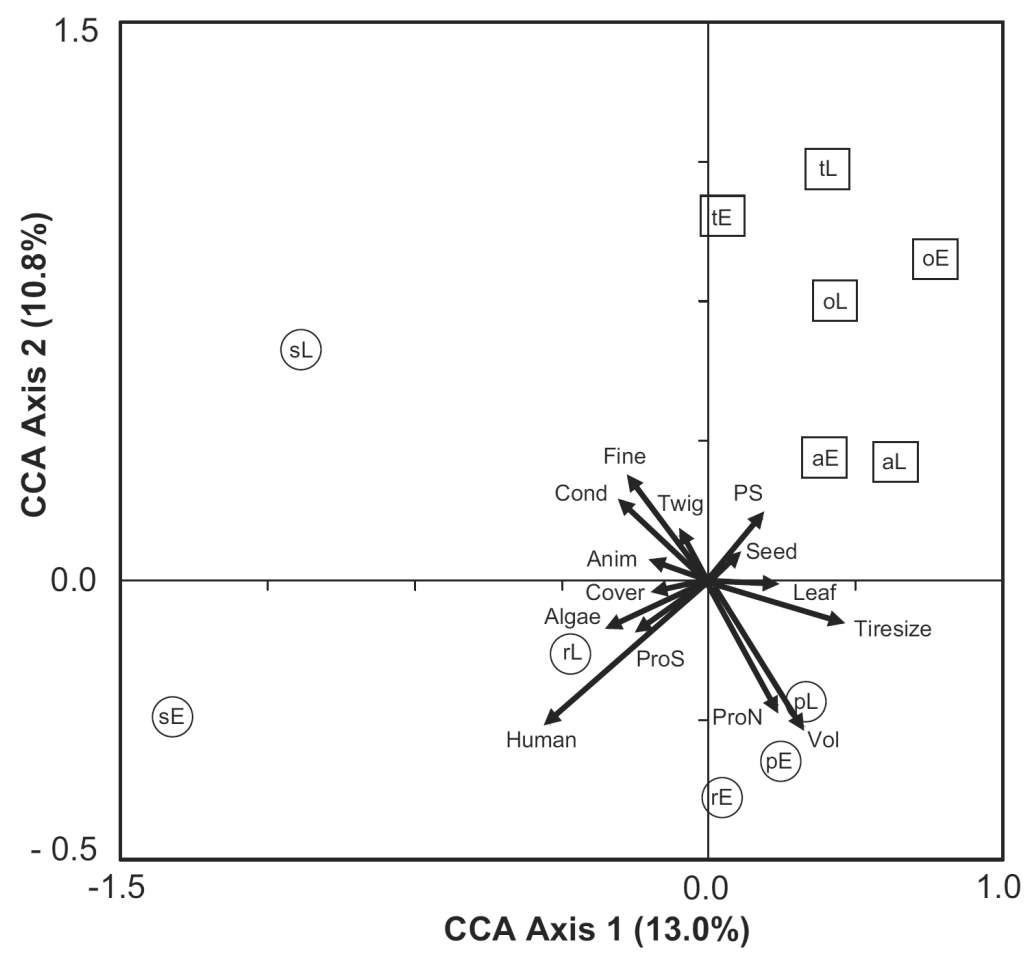

Fig. 2.

CCA biplots for mosquito species and stages and the environmental factors measured in tires in summer (July-August) 2006 for six sites within central Illinois ( $n=65$ tires). For each axis, the amount of variation explained as a part of the total variation in the model is shown. Arrows indicate the direction and relative importance of the environmental factors (Detritus category: Fine, Leaf, Seed [including fruit]); Habitat category (Tiresize - Tire size, Cover Canopy cover, Human - Human density); Microorganism category (ProN - Protozoan abundance, PS - Bacterial productivity via protein synthesis). Species (a - Aedes albopictus, $\mathrm{o}-$ Ae. atropalpus, $\mathrm{t}-$ Ae. triseriatus, $\mathrm{p}-$ Culex pipiens, $\mathrm{r}-C x$. restuans, $\mathrm{s}-C x$. salinarius) and stages ( $\mathrm{E}$ - early instars, $\mathrm{L}$ - late instars) are indicated within symbols. For clarity, Aedes are enclosed in squares, and Culex in circles. 


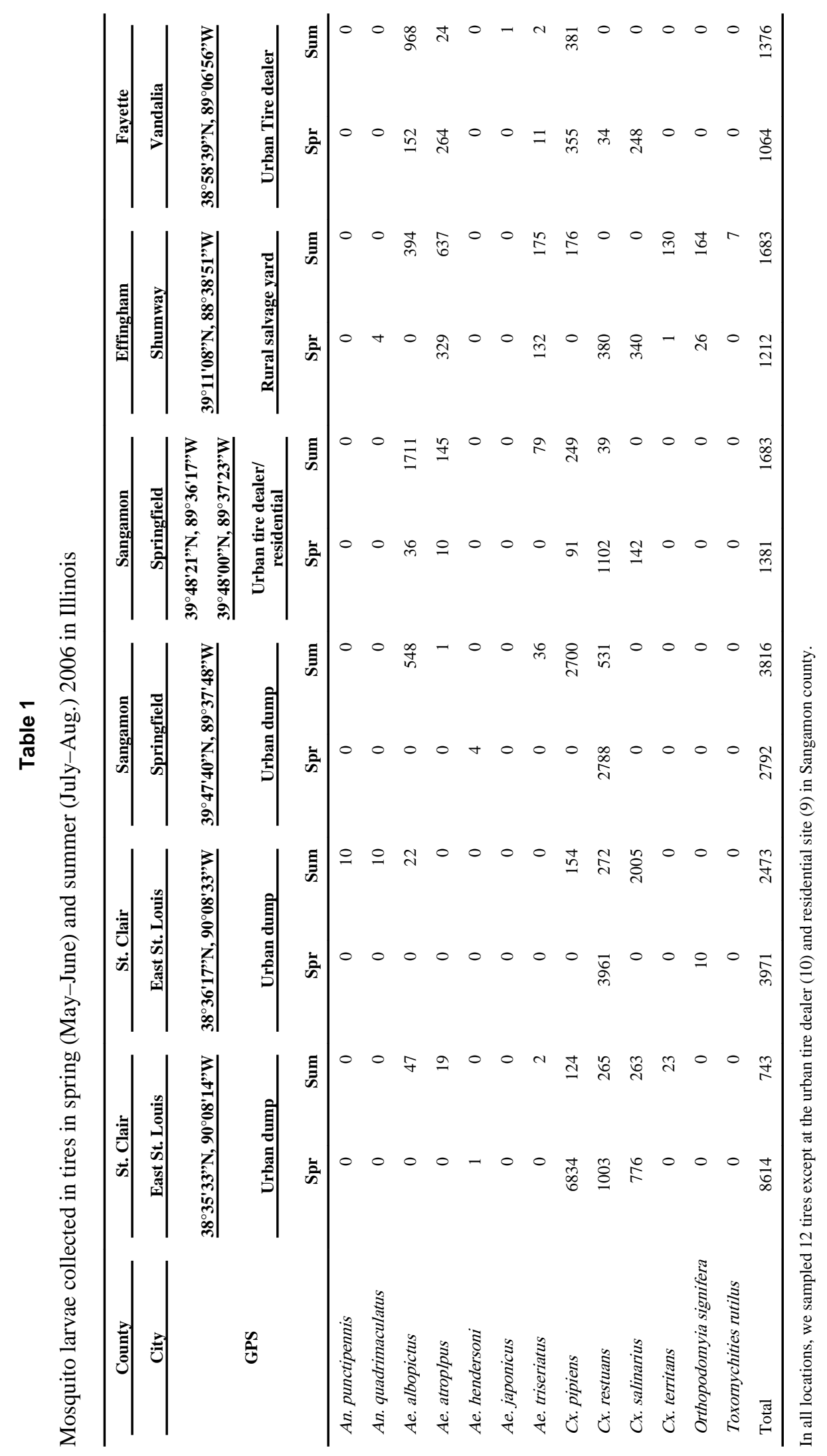

J Med Entomol. Author manuscript; available in PMC 2012 June 18. 


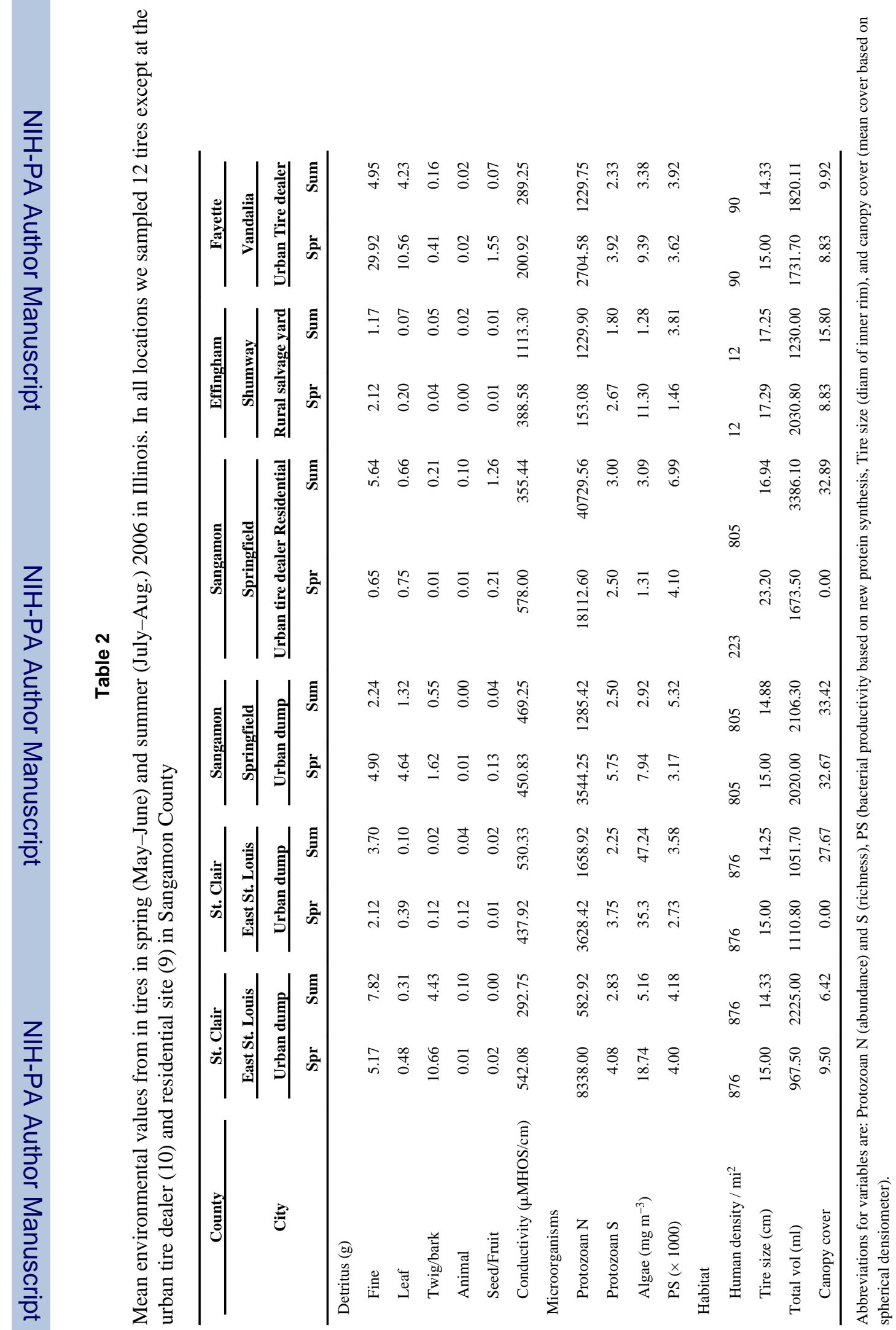

